\title{
Patient Selection and Efficacy of Intradiscal Electrothermal Therapy with Respect to the Dallas Discogram Score
}

\author{
Atilla KIRCELLI, Ilker COVEN, Tufan CANSEVER, Erkin SONMEZ, Cem YILMAZ \\ Baskent University, Faculty of Medicine, Department of Neurosurgery, Ankara, Turkey
}

\section{ABSTRACT}

\begin{abstract}
AIM: Intervertebral disc degeneration can cause severe low back pain. Intradiscal electrothermal therapy (IDET) is a minimally invasive treatment option for patients with symptomatic internal disc disruption unresponsive to conservative medical care. We aimed to evaluate 12-month pain and functional outcomes and predictors of clinical success in patients with discogenic back pain treated with IDET with respect to the Dallas Discogram Scale (DDS).
\end{abstract}

MATERIAL and METHODS: This was a retrospective analysis of patients undergoing IDET for low back pain from 2009 through 2014 at Baskent University, Department of Neurosurgery. A total number of 120 consecutive patients data were collected retrospectively. The degree of disc degeneration was graded using the DDS during discography, and the presence of a high intensity zone (HIZ) on magnetic resonance (MR) imaging was noted. The primary outcome measure was assessment of back pain severity based on the Visual Analogue Scale (VAS); function was assessed by the Oswestry Disability Index (ODI). Follow-up examinations for ODI and VAS scores were assessed at 1, 6, and 12 months post-treatment. Outcomes were discussed with respect to morphological changes in intervertebral discs on discogram.

RESULTS: There was an average $57.39 \%$ and $47.16 \%$ improvement in VAS and ODI scores, respectively, between pretreatment and 12 months follow-up ( $p<0.0001$ for both comparisons). Predictors of 12-month clinical success was depended on DDS ( $p<$ $0.0001)$, a HIZ on MR imaging $(\mathrm{p}<0.0001)$.

CONCLUSION: Durable clinical improvements can be realized after IDET in select surgical candidates with mild disc degeneration and HIZ, discography, and low-grade DDS, with more effective treatment results.

KEYWORDS: Intradiscal electrothermal therapy, Discogenic back pain, Dallas discogram, High intensity zone

\section{INTRODUCTION}

$\mathrm{D}$ isc degeneration is the source of low back pain in approximately half of afflicted patients; facet joints and sacroiliac joints are among the other reported causes in $15-40 \%$ and $13 \%$ of patients, respectively $(14,25)$. Loss of hydration and degenerative changes result in tears of the annulus fibrosus (AF). Outer tears in the AF stimulate neo-vascularization and nociceptors. Inflammation induced by repair mechanisms cause chronic discogenic pain $(2,11)$. Intradiscal electrothermal therapy (IDET) was developed in 1997 as a treatment option for lumbar discogenic pain (22). Symptom- atic annular tears can be treated percutaneously with the minimally invasive IDET procedure.

Disc morphology was first defined by Adams et al., who showed the morphological view of the disc using a discogram (1). The extent and dimensions of the annular tear are thought to be more important than the disc degeneration itself as the basis for discogenic pain based on computed tomography (CT) discography studies.

The Dallas Discogram Classification system was first described in 1980 and modified by Aprill and Bogduk et al. (3) in 1992, and then finally modified in 1996. The Dallas Discogram 
Scale (DDS) for annular disruption was developed to classify each CT discogram to identify the depth of posterior annular disruption (23). Subsequently, Vanharanta et al. reported an association between the tear expansion in the $\mathrm{AF}$ and the degree of pain elicited during discography (29).

This study was undertaken in a neurosurgical setting to evaluate 12-month pain and functional outcomes and predictors of clinical success in patients with discogenic back pain treated with IDET with respect to the DDS and the presence of a high intensity zone (HIZ). There were some studies about the prediction of IDET treatment efficacy under MRI findings, but there was no study to predict the treatment efficacy in terms of discography findings that were modified with the Dallas discogram classification system. Our study showed the efficacy of IDET in long-term period and also affected the low grade DDS score patients.

\section{MATERIAL and METHODS}

This retrospective assessment was conducted in Turkey at the neurosurgery department of a University Hospital. Between 2009 and 2014, a total of 134 consecutive patients were treated with IDET for discogenic low back pain. The study was approved by our local ethic committee and was conducted in accordance with the World Medical Association Declaration of Helsinki of 1964 as revised in 1983 and 2000. All patients were informed about their participation in the study and gave informed consent.

\section{Participants}

We included patients who had undergone IDET, having previously undergone MRI that confirmed the existence of lumbar degenerated disc disease. We performed the IDET procedure in patients that met the inclusion criteria.

\section{Inclusion Criteria}

- Internally-disrupted disc with an annular fissure

- Contained disc herniation

- Discogenic pain diagnosed by low volume provocative discogram

- Preserved disc height $>50 \%$

- Chronic symptoms of 6 months or more

- Failed an aggressive non-operative care plan, including non-steroidal anti-inflammatory drugs, physical therapy, bracing, and injections

\section{Exclusion Criteria}

- Lumbar stenosis

- Extruded and sequestered disc

- Evidence of neural compression on MR imaging

- Previous lumbar surgery

- Overlying psychological issues

- Segmental instability

- Severe loss of disc height $>50 \%$

\section{Intervention}

We used a standard discography technique. An extrapedicular approach was used, in which an 18-gauge introducer with a 22-gauge Chiba needle was inserted into the suspected level(s) and a control level with the patient under light sedation. Correct placement of the needles was confirmed on fluoroscopic imaging. The patient was then awakened and had to be alert and responding appropriately to questioning before proceeding with the test. The discography was considered positive if the patient experienced pain on pressurization with $2.5 \mathrm{~mL}$ of contrast Omnipaque $300 \mathrm{TM}$ (iohexol, $300 \mathrm{mg}$ iodine per milliliter). The discs were assessed for the pattern of dye distribution with respect to DDS, as well as the presence of leakage into the epidural space (Figure 1AE).

The Dallas Discogram Scale is a 5-point scale that specifies the degree of disc degeneration. The Dallas grading system is used to assess the morphological aspects of the disc; Grade 0 indicates a disc in which the contrast agent remains entirely in the nucleus pulposus, Grades 1, 2, and 3 indicate tears in which the contrast agent extends to the innermost, middle, and outermost sections of the AF, respectively. Grade 4 was added later; the Grade 4 fissure has expanded into an arcshaped tear outside of or in the innermost ring of the AF and grade 5 tear describes either a grade 3 or grade 4 radial tear that has completely ruptured that outer layers of the disc and is leaking contrast material out of the disc (Figure 1A-E).

After discography, we performed the IDET procedure using a navigable intradiscal catheter with a thermal resistive coil. Under fluoroscopy guidance, a $30-\mathrm{cm}$ spineCATH catheter (Oratec Interventions, Inc., Menlo Park, CA, USA) with a $5-\mathrm{cm}$ active electrothermal tip was inserted anteriorly into the AF or nucleus pulposus via a needle. The active tip was advanced anterolaterally inside the nuclear tissue and directed circuitously to return posteriorly, providing an ideal position to heat the entire posterior AF. Once a satisfactory position was obtained in the anteroposterior and lateral views, the catheter was connected to a lead and passed to an independent technician. In all cases, the catheter tips were within $5 \mathrm{~mm}$ of the posterior vertebral margin upon review of the saved fluoroscopic films. We used a standard protocol in which heating began at $65^{\circ} \mathrm{C}$ and was increased incrementally by $1^{\circ} \mathrm{C}$ every 30 seconds to achieve a final temperature of $90^{\circ} \mathrm{C}$. The final temperature was maintained for 4 minutes, giving a total treatment time of 16 to 17 minutes before the catheter was removed. The procedure was performed under light sedation as an outpatient procedure. There were no complications or nerve injury during the procedure.

\section{Outcome Evaluation}

Pain outcomes were assessed by the visual analogue scale (VAS) on a 0-100 mm scale, and disability was assessed by the Oswestry disability index (ODI). Follow-up examinations for ODI and VAS scores were conducted at 1, 6, and 12 months post-treatment. The degree of disc degeneration was graded using the DDS, and the presence of a HIZ on MR imaging was also noted. 


\section{Statistical Analyses}

Statistical analyses were performed using SPSS software version 21 (IBM Corp., Armonk, NY, USA). The variables were investigated using visual (histogram, probability plots) and analytical methods (Kolmogorov-Smirnov test) to determine whether they were normally distributed. Descriptive analyses were presented using means and standard deviations for normally distributed variables. One-way ANOVA was used to compare parametric values, DDS between pre- and postoperative VAS and ODI scores. The Levene test was used to assess the homogeneity of the variances. The chi-square test was used to compare non-parametric values. An overall $p$ value of $<0.05$ was considered statistically significant. When an overall significance was observed, pairwise post hoc tests were performed using Tukey's test.

\section{RESULTS}

We identified 134 consecutive patients who had undergone IDET, but excluded 14 who were lost to follow-up. The 120 patients consisted of 53 female and 67 male patients. The mean age of the women was $33.08 \pm 6.61$ years, and the mean age of the men was $33.8 \pm 6.26$ years. We performed IDET most frequently at the L4-L5 level. The groups were similar in terms of age, gender, VAS and ODI scores of intervertebral disc levels at 12 months (Table I).
Patients presented with severe back pain at baseline experienced a marked improvement after IDET that was sustained through 12 months of follow-up. Although the improvements in VAS and ODI scores after the first month demonstrated the $p$ values nearest to the significant value ( $p=0.053$ for VAS, and $p=0$ for ODI), significant improvement was observed after the first month. At the 6 and 12 months follow-up, the VAS had improved significantly compared with baseline ( $p=0.000$ and $p=0.007$, respectively), as had the ODI (both $p=0.000$ )

Patients were separated into groups according to their DDS for analysis. There was a significant difference between the preoperative VAS scores for all groups except

DDS1 patients compared with DDS2 patients $(p=0.362)$,

DDS3 compared with DDS4 ( $p=1.0)$,

DDS3 compared with DDS5 $(p=0.982)$,

DDS4 compared with DDS5 $(p=1.0)$.

At 1 month post-treatment there was no significant difference in VAS score between the Dallas Discogram groups. At $6^{\text {th }}$ and 12 months post-treatment there was a significant difference in VAS scores between all Dallas Discogram groups, except; DDS1 compared with DDS2 $(p=0.964$ after 6 months, and $p=0.872$ after 12 months) and DDS3 compared with DDS4 ( $p=1.0$ after 6 months, and $p=0.846$ after 12 months).
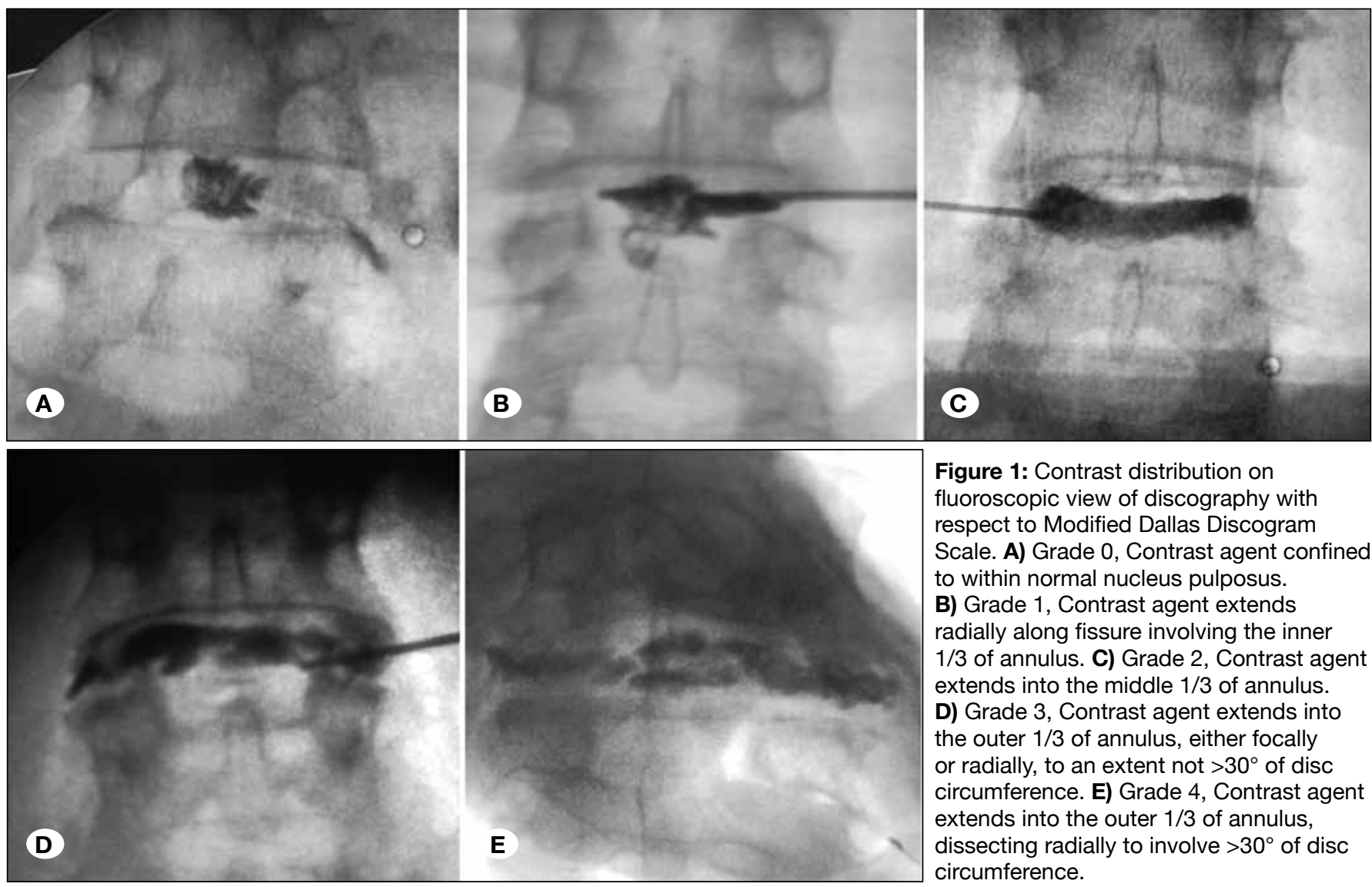

Figure 1: Contrast distribution on fluoroscopic view of discography with respect to Modified Dallas Discogram Scale. A) Grade 0, Contrast agent confined to within normal nucleus pulposus. B) Grade 1, Contrast agent extends radially along fissure involving the inner $1 / 3$ of annulus. C) Grade 2, Contrast agent extends into the middle $1 / 3$ of annulus. D) Grade 3, Contrast agent extends into the outer $1 / 3$ of annulus, either focally or radially, to an extent not $>30^{\circ}$ of disc circumference. E) Grade 4, Contrast agent extends into the outer $1 / 3$ of annulus, dissecting radially to involve $>30^{\circ}$ of disc circumference. 
Table I: Demographic Factors and Their Effects on the $12^{\text {th }}$ Month Outcome Scores

\begin{tabular}{|c|c|c|c|}
\hline Demographic Factors & & VAS $12^{\text {th }}$ & ODI $12^{\text {th }}$ \\
\hline Sex & Female $=53(44.2 \%) /$ Male $=67(55.8 \%)$ & $p=0.436$ & $p=0.804$ \\
\hline L3-4 & $\mathrm{n}=5(4.2 \%)$ & \multirow{2}{*}{$p=0.48$} & \multirow{2}{*}{$p=0.34$} \\
\hline$\llcorner 4-5$ & $\mathrm{n}=83(69.2 \%)$ & & \\
\hline \multicolumn{2}{|l|}{ Dallas discogram scores } & \multirow{4}{*}{$p<0.0001$} & \multirow{4}{*}{$p=0.003$} \\
\hline Dallas 1 & $\mathrm{n}=50(41.7 \%)$ & & \\
\hline Dallas 2 & $\mathrm{n}=28(23.3 \%)$ & & \\
\hline Dallas 3 & $n=16(13.3 \%)$ & & \\
\hline Positive & $\mathrm{n}=77(64.2 \%)$ & \multirow[t]{2}{*}{$p<0.0001$} & \multirow[t]{2}{*}{$p=0.002$} \\
\hline Negative & $n=43(35.8 \%)$ & & \\
\hline
\end{tabular}

There was a significant difference between all Dallas Discogram groups (pre-treatment ODI, 1 month ODI, 6 month ODI, 12 month ODI) with respect to ODI scores ( $p=0.000$ for all groups). Regarding the pre-treatment ODI scores, there was a significant difference between all Dallas Discogram groups except;

DDS1 compared with DDS2 ( $p=0.998)$,

DDS3 compared with DDS4 ( $p=0.979)$,

DDS3 compared with DDS5 ( $p=0.998)$,

and DDS4 compared with DDS5 $(p=0.926)$.

Regarding the ODI scores at 1 month post-treatment, there was no significant difference between the Dallas Discogram groups. At 6 and 12 months post-treatment, there was a significant difference in ODI scores between all Dallas Discogram groups except DDS1 compared with DDS2 ( $p=0.968$ after 6 months, and $p=0.958$ after 12 months), and DDS3 compared with DDS4 $(p=0.475$ after 6 months, and $p=0.35$ after 12 months) (Figure 2).

The mean VAS scores improved from $69.25 \pm 7.46$ pretreatment $(n=120)$ to $30.92 \pm 11.52$ at 6 months post-treatment $(n=120, p<0.0001)$, and $29.83 \pm 12.02$ at 12 months posttreatment $(n=120, p<0.0001)$; this represents an overall mean difference average improvement in VAS of $57.39 \%$. The mean improvement in pain severity was $55.35 \%$ and $56.93 \%$ at 6 and 12 months post-treatment, respectively.

Patients also experienced similar improvements in back function. The mean ODI scores improved from $56.9 \pm 6.9 \%$ pretreatment $(n=120)$ to $30.4 \pm 11.51 \%$ at 12 months followup. The mean improvement in ODI was $47.16 \pm 17.15 \%$ at 12 months follow-up $(n=120)$.
There were 77 patients were $\mathrm{HIZ}+$ on MR imaging (64.3\%) out of the 120 total patients; the mean percentage improvement in ODI at 12 months post-treatment for $\mathrm{HIZ}$ + patients was $28 \%$, compared with a $24 \%$ improvement in ODI for patients without HIZ ( $n=43)$. Similarly, the mean percent improvement in VAS score at 12 months was $41 \%$ for $\mathrm{HIZ}$ + patients, compared with $35 \%$ for HIZ- negative patients. Strong and noteworthy associations were also found between clinical success rate, and the degree of HIZ.

Clinical success rate was determined as the percentage change between the pretreatment and 12 months mean follow up VAS and ODI scores; the patients who improved $50 \%$ or more were considered treatment success. The VAS treatment success rates were $67.13 \% \pm 5.76$ and $67.18 \% \pm$ 5.80 respectively for DDS $1(n=50)$ and DDS $2(n=28)$ patients, and all DDS 3-4-5 treatment success rates were under $50 \%$. Similarly, the ODI treatment success rates were $56.43 \pm 6.46 \%$ and $58.11 \pm 8.74 \%$ respectively for DDS1 and DDS2 patients groups, and treatment success rate for all DDS 3-4-5 remained under $50 \%$. There were no differences between DDS1 and DD2 patient groups with or without HIZ were effected to the VAS and ODI treatment scores (Figure 3).

$\mathrm{HIZ}+$ patient group mean VAS score was $61.23 \pm 12.75 \%$, and mean ODI score was $50.70 \pm 13.86 \% \mathrm{HIZ}$ - patient group mean VAS $50.52 \pm 16.55 \%$, and ODI was $40.81 \pm 20.53 \%$. There were significant differences between the $\mathrm{HIZ}+$ and $\mathrm{HIZ}-\mathrm{VAS}$ groups and $\mathrm{HIZ}+$ and $\mathrm{HIZ}-\mathrm{ODI}$ groups $(\mathrm{p}<0.0001$ and $\mathrm{p}=0.002$ respectively) (Figure 3).

In the HIZ+ patient group, DDS $1(\mathrm{n}=38)$ and DDS $2(\mathrm{n}=21)$ patients' mean VAS treatment success scores were $67.15 \pm 5.4 \%$ and $67.46 \pm 5.28 \%$ and mean ODI treatment success scores were $56.40 \% \pm 6.85$ and $56.87 \% \pm 8.38$. In 
DDS3-4-5 patients mean VAS and ODI treatment success scores were remained under 50\% (Figure 3).

In HIZ- patient group, DDS 1 ( $\mathrm{n}=12)$ and DDS $2(\mathrm{n}=7)$ patient's mean VAS treatment success scores were \% 67.06 \pm 7.05 and $66.32 \pm 7.58 \%$, mean ODI treatment success scores were $56.52 \pm 5.32$ and $61.80 \pm 9.40$. In DDS3 $-4-5$ patients, mean
VAS and ODI treatment success scores remained under $50 \%$ (Figure 3).

There were no complications during the IDET procedures, and no post-procedural adverse events such as infection or neurological sequelae were reported.

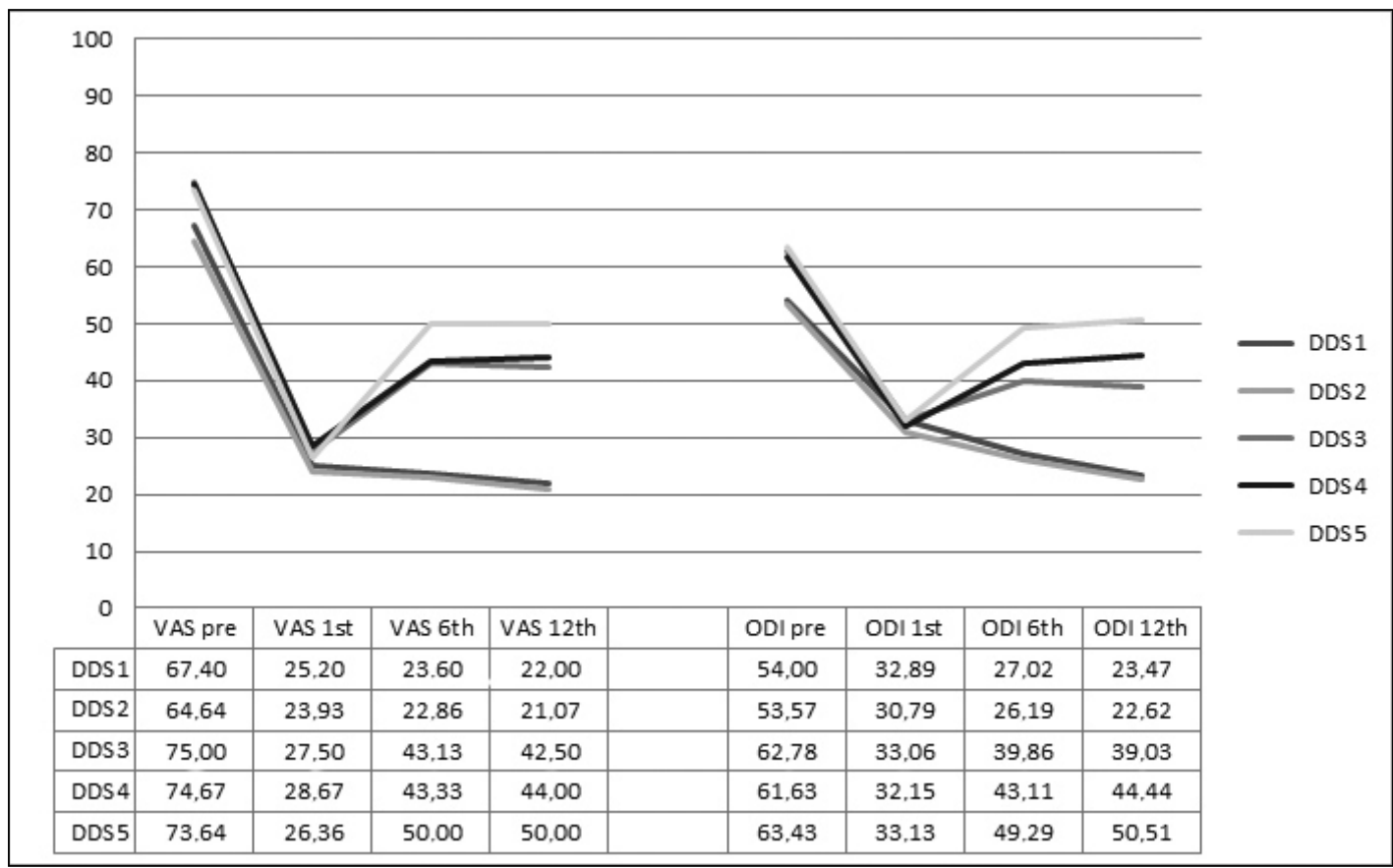

Figure 2: Dallas discogram scale relation with visual analogue scale (VAS) and Oswestry Disability Index (ODI) score improvements for months.

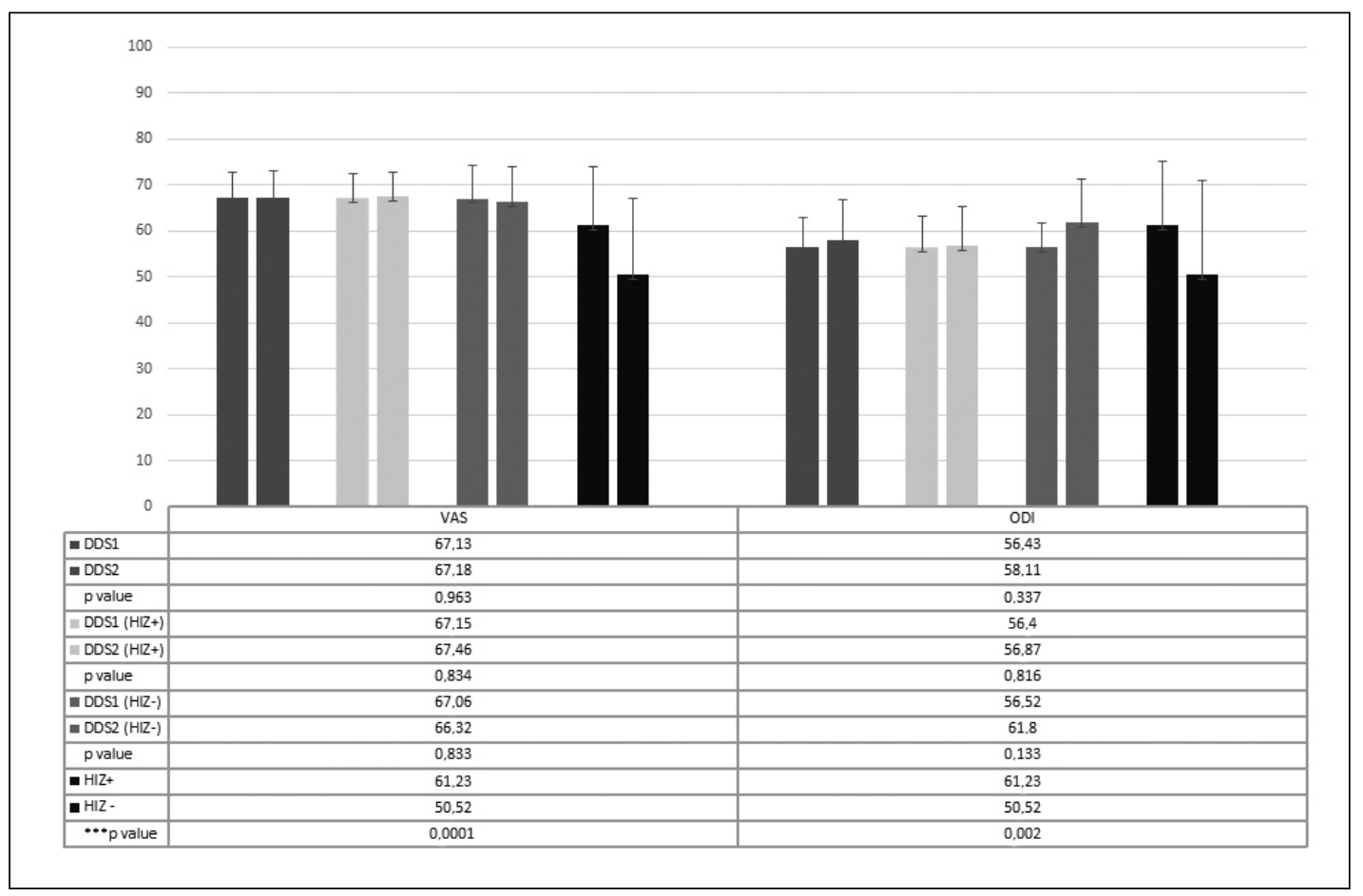

Figure 3: VAS and ODI treatment success rates relation between DDS and HIZ (DDS: Modified Dallas discogram scale, HIZ: High intensity zone, ODI: Oswestry disability index, VAS: Visual analogue scale) 


\section{DISCUSSION}

Chronic low back pain is difficult to diagnose and treat clinically, and discogenic low back pain treatment is still controversial. In cases where continuous low back pain has remained for 6 months and is unresponsive to aggressive non-operative interventions, there is only a low chance of spontaneous resolution. This study describes the clinical outcome of 120 patients with chronic low back pain whose symptoms did not improve with aggressive non-operative care. The clinical inclusion criteria for patients undergoing IDET were those with discogenic low back pain and concordant pain reproduction on lumbar discography $(12,16,33)$. IDET appears to be a successful minimally invasive option for patients with chronic discogenic low back pain (that has failed to improve with a comprehensive, exercise-based non-operative care program), and who desire functional improvement but would prefer to avoid fusion surgery or long-term opioids (2).

Post-discography CT imaging was used to grade the extent of annular disruption according to the modified Dallas Discogram classification $(23,27)$. Discography is currently the only available imaging method for investigating annular disruption, and internal disc degeneration changes are commonly measured by morphological changes on MR imaging (18). Discography gives trusted results regarding the relationship between discogenic pain and internal disc morphology. Unfortunately, even high-resolution MR imaging fails to visualize the internal architecture of the disc. Disc degeneration classification using imaging not designed to detect the structural changes inside the disc has limitations regarding the ability to localize the degenerative changes $(19,20)$.

Elastance measured during discography showed significant differences between normal and degenerative discs. There was a statistically significant change between Grade 0 and Grade 4 and 5. Vanharanta et al. noted that the pain response elicited by discography correlates with the extent of annular disruption $(27,30)$. Discography on normal or Grade 1 discs rarely produces pain, yet discography on discs Grade 3 and higher usually provokes a pain response. In Grade 3 AF ruptures, more than $75 \%$ of discographies are accompanied by the exact reproduction of concordant pain. It has been shown that in pain reproduction during discography, $77 \%$ of the discus intervertebrales have an internal morphology with a Grade 3 rupture. This concordant pain is also present very intermittently in Grade 2 ruptures (29).

In our study, there were no significant differences between patients with a DDS score of 1 versus 2 , and those with a DDS of 3 versus 4 . The pain scores for those classified as DDS 1 were similar to those classified as DDS 2, and DDS 3 and 4 patients also had similar pain scores.

IDET involves using a navigable intradiscal catheter that is radiologically guided into the outer posterior and posterolateral AF across a previously identified tear, and has the ability to treat patients with lumbar disc annular disease that have been unresponsive to conservative management $(4,6,7)$. A temperature-controlled thermal resistive coil provides conductive heating of the $A F$ in a range that leads to denatur- ation of collagen fibers, cauterization of granulation tissue, and coagulation of nerve fibers $(5,8,26,28)$. IDET produced sufficient temperatures to induce collagen denaturation and coalescence in human cadaveric lumbar discs (31). Freeman et al. also showed adequate temperatures in an in vivo model to theoretically perform both coagulation of nociceptors and contraction of collagen $(9,26)$.

IDET led to a good outcome at the 6 and 12-month followup examinations, although the first month VAS scores were near to non-significant levels. All pre- and post-operative pain scores showed the similarity between DDS 1 and 2 patients, and those with high-grade DDS.

In patients with low back pain, a reliable marker of painful outer annular disruption seems to be the presence of a highintensity zone (HIZ) (17); this is an area of high intensity within the posterior AF seen on T2-weighted, sagittally-oriented MR imaging sequences (3). Lam et al. considered the HIZ to be a reflection of the edge of neovascularization of the posterior $\mathrm{AF}$ or a healing annular tear (15). Almost all HIZ-positive (HIZ+) discs in a previous study were morphologically abnormal on discography; Grade 3 morphology exhibited frequently (15).

We found that $64 \%$ of total patients were $\mathrm{HIZ+}$, and that all $\mathrm{HIZ}+$ patients were in the DDS 1 and 2 groups. On MR imaging, $\mathrm{HIZ}+$ patients showed a better outcome compared with HIZ-negative patients. One of the major compositional changes in disc degeneration is the loss of proteoglycan due to a lower ability to maintain hydration under load-bearing forces. The water content decreases in degenerated discs with respect to normal discs. Additionally, annular disruption and fissuring of the collagen matrix causes the formation of a HIZ. Collagen modulation and shrinkage of the disc with potential stabilization have been proposed as a possible mechanism of action of IDET. IDET acts via heat energy on discs with a higher water content (less degenerated discs), reducing disc compression (17). As a result of decreasing the water content of the disc due to disc degeneration progress, the IDET treatment could be less effective in DDS 3, DDS 4 and DDS 5 patients.

We have seen the shrinkage effect of IDET in post-intervention MR images in some patients, and these images revealed the regression of the degenerative disc disease (Figure 4A, B).

IDET complications are extremely rare. There was a relevant conducted review (5 different spine centers, 1675 IDET procedure) root injury in 6 patients, post-IDET disc herniation in 6 patients, catheter fracture in 19 patients (catheter breakage) such complications have been observed. This review was not revealed discitis (21). This review also reported rare complications such as skin burns and bladder dysfunction.

Another study has reported different complications after IDET such as discitis and neural injury (13), post-IDET cauda equina syndrome $(10,32)$, and heat injury related endplate necrosis (24).

The limitations of this study are those inherent to any retrospective study, and include selection bias and lack of a control group. This study focused on the therapeutic efficacy of 


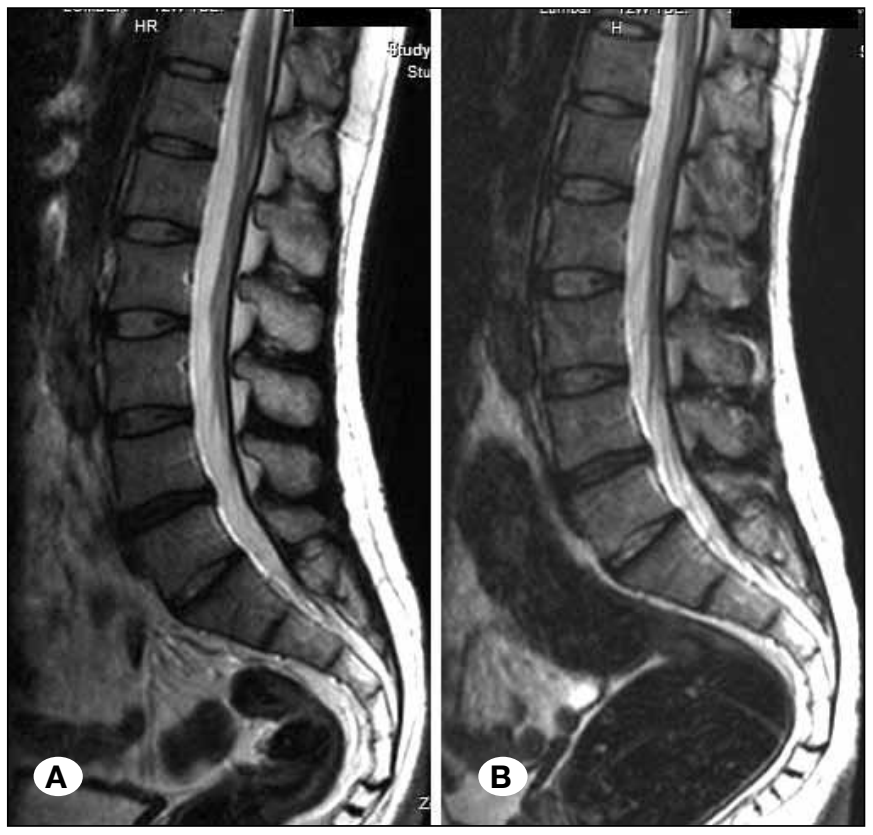

Figure 4: Pre-intervention (A) and post-intervention (B) T2 weighted sagittal magnetic resonance images. Decreasing degeneration, and shrinkage of the disc after intervention were seen (B).

IDET procedure in only a select group of patients. Additionally, the number of patients included for long-term evaluation was greatly limited by the fact that most patients are yet to complete the program. However, the long-term (12 month) followup was sufficient to evaluate the therapeutic effect of IDET.

Our principal findings were that IDET achieved a significantly greater improvement in pain score in later post-treatment months, and it was not useful on patients of DDS 3, 4 and 5. Future research is needed to investigate the effects of IDET in a randomized and placebo-controlled trial.

\section{- CONCLUSION}

Patients in this study were grouped according to the DDS. The findings suggest that durable clinical improvements can be realized after IDET in highly select surgical candidates with mild disc degeneration, discography, and low-grade DDS. The benefits of IDET were found to provide a more effective treatment in patients with lower DDS and in $\mathrm{HIZ}+$ patients with chronic low back pain.

\section{REFERENCES}

1. Adams $M$, Dolan $P$, Hutton $W$ : The stages of disc degeneration as revealed by discograms. J Bone Joint Surg Br 68-B:36-41, 1986

2. Andersson GB, Mekhail NA, Block JE: Treatment of intractable discogenic low back pain. A systematic review of spinal fusion and intradiscal electrothermal therapy (IDET). Pain Physician 9:237-248, 2006

3. Aprill $\mathrm{C}$, Bogduk N: High-intensity zone: A diagnostic sign of painful lumbar disc on magnetic resonance imaging. $\mathrm{Br} \mathrm{J}$ Radiol 65:361-369, 1992
4. Assietti R, Morosi M, Block JE: Intradiscal electrothermal therapy for symptomatic internal disc disruption: 24-month results and predictors of clinical success. J Neurosurg Spine 12:320-326, 2010

5. Bono CM, Iki K, Jalota A, Dawson K, Garfin SR: Temperatures within the lumbar disc and endplates during intradiscal electrothermal therapy: Formulation of a predictive temperature map in relation to distance from the catheter. Spine (Phila Pa 1976) 29:1124-1129; discussion 1130-1131, 2004

6. Bridwell $\mathrm{KH}$, Anderson PA, Boden SD, Vaccaro AR, Zigler JE: What's new in spine surgery. J Bone Joint Surg Am 86a:1587-1596, 2004

7. Brodke DS, Ritter SM: Nonoperative management of low back pain and lumbar disc degeneration. J. Bone Joint Surg Am 86:1810-1818, 2004

8. Derby R, Baker RM, Lee CH, Anderson PA: Evidence-informed management of chronic low back pain with intradiscal electrothermal therapy. Spine J 8:80-95, 2008

9. Freeman BJC, Fraser RD, Cain CMJ, Hall DJ, Chapple DCL: A randomized, double-blind, controlled trial: Intradiscal electrothermal therapy versus placebo for the treatment of chronic discogenic low back pain. Spine 30:2369-2377, 2005

10. Hsia AW, Isaac K, Katz JS: Cauda equina syndrome from intradiscal electrothermal therapy. Neurology 55:320, 2000

11. Kloth DS, Fenton DS, Andersson GB, Block JE: Intradiscal electrothermal therapy (IDET) for the treatment of discogenic low back pain: Patient selection and indications for use. Pain Physician 11:659-668, 2008

12. Knox BD, Chapman TM: Anterior lumbar interbody fusion for discogram concordant pain. J Spinal Disord 6:242-244, 1993

13. Konno S, Olmarker K, Byrod G, Nordborg C, Stromqvist B, Rydevik B: The European Spine Society AcroMed Prize 1994. Acute thermal nerve root injury. Eur Spine J 3:299-302, 1994

14. Kuslich SD, Ulstrom CL, Michael CJ: The tissue origin of low back pain and sciatica: A report of pain response to tissue stimulation during operations on the lumbar spine using local anesthesia. Orthop Clin North Am 22:181-187, 1991

15. Lam KS, Carlin D, Mulholland RC: Lumbar disc high-intensity zone: The value and significance of provocative discography in the determination of the discogenic pain source. Eur Spine J 9:36-41, 2000

16. Lee CK, Vessa P, Lee JK: Chronic disabling low back pain syndrome caused by internal disc derangements. The results of disc excision and posterior lumbar interbody fusion. Spine (Phila Pa 1976) 20:356-361, 1995

17. Peng B, Hou S, Wu W, Zhang C, Yang Y: The pathogenesis and clinical significance of a high-intensity zone $(\mathrm{HIZ})$ of lumbar intervertebral disc on MR imaging in the patient with discogenic low back pain. Eur Spine J 15:583-587, 2006

18. Pfirrmann CWA, Metzdorf A, Zanetti M, Hodler J, Boos N: Magnetic Resonance Classification of lumbar intervertebral disc degeneration. Spine 26:1873-1878, 2001

19. Resnick DK, Choudhri TF, Dailey AT, Groff MW, Khoo L, Matz PG, Mummaneni P, Watters WC 3rd, Wang J, Walters BC, Hadley MN: Guidelines for the performance of fusion procedures for degenerative disease of the lumbar spine. Part 6: Magnetic resonance imaging and discography for patient selection for lumbar fusion. J Neurosurg Spine 2:662-669, 2005 
Kircelli A. et al: Intradiscal Electrothermal Therapy

20. Resnick DK, Malone DG, Ryken TC: Guidelines for the use of discography for the diagnosis of painful degenerative lumbar disc disease. Neurosurg Focus 13:E12, 2002

21. Saal JA, Saal JS, Wetzel FT, Thompson K, Maurer $P$, JH: IDET related complications: A multi-center study of 1675 treated patients with a review of the FDA MDR data base, in Proceedings of the North American Spine Society 16th Annual Meeting. Seattle, Washington, USA, October 31-November 3, 2001

22. Saal JA, Saal JS: Intradiscal electrothermal treatment for chronic discogenic low back pain: A prospective outcome study with minimum 1-year follow-up. Spine (Phila Pa 1976) 25:2622-2627, 2000

23. Sachs BL, Vanharanta $H$, Spivey MA, Guyer RD, Videman T, Rashbaum RF, Johnson RG, Hochschuler SH, Mooney V: Dallas discogram description. A new classification of CT/ discography in low-back disorders. Spine (Phila Pa 1976) 12:287-294, 1987

24. Scholl BM, Theiss SM, Lopez-Ben R, Kraft M: Vertebral osteonecrosis related to intradiscal electrothermal therapy: A case report. Spine (Phila Pa 1976) 28:E161-164, 2003

25. Schwarzer AC, Aprill CN, Derby R, Fortin J, Kine G, Bogduk N: The relative contributions of the disc and zygapophyseal joint in chronic low back pain. Spine (Phila Pa 1976) 19:801-806, 1994
26. Shah RV, Lutz GE, Lee J, Doty SB, Rodeo S: Intradiskal electrothermal therapy: A preliminary histologic study. Arch Phys Med Rehabil 82:1230-1237, 2001

27. Shin DA, Kim HI, Jung JH, Shin DG, Lee JO: Diagnostic relevance of pressure-controlled discography. J Korean Med Sci 21:911-916, 2006

28. Singh V: Intradiscal electrothermal therapy: A preliminary report. Pain Physician 3:367-373, 2000

29. Vanharanta H, Sachs BL, Spivey MA, Guyer RD, Hochschuler SH, Rashbaum RF, Johnson RG, Ohnmeiss D, Mooney V: The relationship of pain provocation to lumbar disc deterioration as seen by CT/discography. Spine (Phila Pa 1976) 12:295298, 1987

30. Vanharanta H, Videman T, Sachs B, Spivey M: Computed tomography and discography in patients with spinal symptoms. Duodecim 104:917-922, 1988

31. Wegener B, Rieskamp K, Buttner A, Habiyambere V, von Schultze-Pellangahr C, Schaffer V, Jansson V, Birkenmaier C: Experimental evaluation of the risk of extradiscal thermal damage in intradiscal electrothermal therapy (IDET). Pain Physician 15:E99-e106, 2012

32. Wetzel FT: Cauda equina syndrome from intradiscal electrothermal therapy. Neurology 56:1607, 2001

33. Wetzel FT, LaRocca SH, Lowery GL, Aprill CN: The treatment of lumbar spinal pain syndromes diagnosed by discography. Lumbar arthrodesis. Spine (Phila Pa 1976) 19:792-800, 1994 